\title{
Seroprevalence of the SARS-CoV-2 antibody in healthcare workers: a multicentre cross-sectional study in 10 Colombian cities
}

\author{
Jeadran Nevardo Malagón-Rojas (1) ,1,2 Marcela Mercado-Reyes, ${ }^{3}$ \\ Yezith G Toloza-Pérez (10) , ${ }^{2}$ Eliana L Parra Barrera (1) , ${ }^{2}$ Marien Palma (D) , \\ Esperanza Muñoz, ${ }^{4}$ Ronald López (D) , Julia Almentero (D) , ${ }^{2}$ Vivian V Rubio (D) , \\ Edgar Ibáñez, ${ }^{5}$ Eliana Téllez (D) , 2,6 Lucy G Delgado-Murcia (D) , ${ }^{7}$ Claudia P Jimenez, 8,9 \\ Diego Viasus-Pérez (D) , ${ }^{10}$ Marisol Galindo (D) , ${ }^{3}$ Luisa Lagos (D) , ${ }^{2}$ Interinstitutional \\ Support Group
}

\begin{abstract}
- Additional supplemental material is published online only. To view, please visit the journal online (http://dx.doi. org/10.1136/oemed-2021 107487).
\end{abstract}

For numbered affiliations see end of article.

Correspondence to Dr Jeadran Nevardo MalagónRojas, Grupo de investigación en Salud Ambiental y Laboral, Instituto Nacional de Salud, Bogota, Colombia;

jnmalagon@unbosque.edu.co

Received 18 February 2021 Accepted 14 October 2021

Check for updates

(c) Author(s) (or their employer(s)) 2021. Re-use permitted under CC BY-NC. No commercial re-use. See rights and permissions. Published by BMJ.

To cite: Malagón-Rojas JN, Mercado-Reyes $\mathrm{M}$

Toloza-Pérez YG, et al. Occup Environ Med Epub

ahead of print: [please include Day Month Year]. doi:10.1136/ oemed-2021-107487

\section{ABSTRACT}

Background Healthcare workers are at increased risk of infection due to occupational exposure to SARSCoV-2-infected patients. The objective of this study was to determine the seroprevalence of SARS-CoV-2 in healthcare workers in Colombia.

Methods This study is a cross-sectional study focused on estimating the seroprevalence of SARS-CoV-2 antibodies in healthcare workers from 65 hospitals in 10 cities in Colombia during the second semester of 2020. The seroprevalence was determined using an automated immunoassay (Abbott SARS-CoV-2 CLIA lgG). The study included a survey to establish the sociodemographic variables and the risk of infection. A multivariate model was used to evaluate the association between the results of seroprevalence and risk factors.

Results The global seroprevalence of antibodies against SARS-CoV-2 was 35\% (95\% Bayesian CI 33\% to $37 \%$ ). All the personnel reported the use of protective equipment. General services personnel and nurses presented the highest ratios of seroprevalence among the healthcare workers. Low socioeconomic strata have shown a strong association with seropositivity.

Conclusion This study estimates the prevalence of SARS-CoV-2 infection among healthcare workers. Even though all the personnel reported the use of protective equipment, the seroprevalence in the general services personnel and nurses was high. Also, a significant difference by cities was observed.

\section{INTRODUCTION}

SARS-CoV-2 has generated multiple and diverse challenges worldwide in all areas of work. One of the work environments that has attracted the most attention is the provision of health services, given the relevance of healthcare workers (HCWs) and their role during the pandemic. HCWs possibly have the highest exposure and risk of infection because they are in direct contact with infected patients. The WHO estimates that around 14\% of reported COVID-19 cases correspond to HCWs even reaching 35\% in some countries. ${ }^{1}$ By September 2020, in the Americas region, almost 570000
Key messages

What is already known about this subject?

- Worldwide, healthcare workers (HCWs) have been mainly affected due to the direct contact with patients with COVID-19.

- Serological studies are essential to understand the infection in healthcare and to establish control strategies.

- Studies have estimated that the seroprevalence of antibodies against SARS-COV-2 in health workers is highly variable and is correlated with the proportion of infections at the local level.

- Latin America has one of the highest rates of COVID-19 infection among HCWs; except for some reports from specific hospitals, there is a lack of studies of seroprevalence on this group of workers in the region.

What are the new findings?

- The present study was carried out during the second semester of 2020.

- We reported a seroprevalence rate of SARSCoV-2 of $35 \%$ in HCWs, one of the higher ratios of HCWs reported worldwide.

- The SARS-CoV-2 seroprevalence in HCWs varied in the Colombian cities from $21 \%$ to $71 \%$.

- Workers from general services and nurses showed greater seroprevalence ratios.

How might this impact on policy or clinical practice in the foreseeable future?

- Guidance for prevention of the transmission of SARS-CoV-2 may include extra labour factors, such as recommendations for the protection of close relatives and the promotion of protective behaviours out of working hours.

HCWs were reported with COVID-19, in addition to 2500 deaths from SARS-CoV-2. ${ }^{2}$ Around the world, it is estimated that the COVID-19 infections among this specific group range between $1 \%$ and $45.3 \%$, being higher in countries from the northern 
hemisphere. ${ }^{3-10}$ It was indicated that HCWs who are male and from ethnic minorities resulted in higher seroprevalence level. ${ }^{11}$

By 1 July 2021, nearly 4.4 million cases and more than 110000 COVID-19-related deaths have been reported in Colombia. ${ }^{12}$ The country has experienced three peaks: the first between July and August 2020, the second between December 2020 and January 2021, and the last one between April and June 2021. The average effective reproductive number (R0) for the country during 2020 was 1.09 , while the estimated average R0 between January and July 2021 was $0.92 .^{12}$ During the lockdown period, the Colombian health system increased its capability of intensive care unit (ICU) beds number and boosted HCWs' response, as well as the number of labs able to carry out RT-PCR in the country.

Since the pandemic declared by the WHO began in March $2020,{ }^{13}$ various active surveillance strategies have been implemented, such as self-reporting of symptoms through mobile applications, the usage of RT-PCR tests regularly and performing serological tests to the identification of antibodies against SARSCoV-2. ${ }^{14}$ Due to the costs of surveillance strategies through the identification of nucleic acids, this type of intervention has been poorly adopted among health institutions. Given that up to 50\% of SARS-CoV-2 cases correspond to asymptomatic infections, ${ }^{15}$ the incidence of SARS-CoV-2 cases based on the notification of confirmed SARS-CoV-2 cases implies a considerable underestimation of the incidence of this virus infection. ${ }^{16}$ In this sense, the carrying out of studies allowed us to estimate the proportion of HCWs who have antibodies against SARS-CoV-2. Besides, this type of analysis also provides information about the immune response to the virus, natural susceptibility, as well as useful information when prioritising the application of the vaccine.

HCWs are the most exposed to the risk of infection with the new SARS-CoV-2. This study aimed to determine the seroprevalence of antibodies against SARS-CoV-2 among HCWs in Colombia, along with describing the associations between seroprevalence and occupational exposure to SARS-CoV-2 in 10 Colombian cities.

\section{MATERIALS AND METHODS}

This was a cross-sectional study of HCWs across medical services in 10 cities of Colombia from September to November 2020. The study was designed following the recommendations from the Strengthening the Reporting of Observational Studies in Epidemiology statement for observational studies. ${ }^{17}$

\section{SAMPLE}

A cross-sectional study with non-probability sampling was designed for health workers from public and private hospitals in 10 cities in Colombia. To calculate the sample size, an expected seroprevalence of $30 \%(\mathrm{p}=0.30),(\mathrm{q}=1-0.30=0.70)$ was taken with a marginal sampling error of $\pm 2 \%(\delta=0.02)$ and a confidence level $=95 \%(\alpha=0.05, Z \alpha=1.96)$. A $10 \%$ loss percentage was established to calculate a minimum sample size of 2241 participants. We used the definition of HCW designated by the WHO providers of healthcare attention. ${ }^{18}$ The public and private hospitals (IPS) were chosen using the municipal records, choosing the clinics and hospitals that concentrated $80 \%$ of the attention of COVID-19 cases in the municipality. Health workers were invited to participate through the personnel office. Participants in the study were selected from a list of volunteers in each IPS. The selection was performed using a random number generator in Excel. We included personnel either directly or indirectly involved in the healthcare attention: doctors, nurses, pharmacists, physiotherapists, respiratory therapists, bacteriologists, healthcare technicians, admission assistants, general services (catering and cleaning staff), and security personnel. ${ }^{18}$

\section{SERUM SAMPLES AND SEROLOGICAL TEST}

Serum samples obtained from 6 to $7 \mathrm{~mL}$ of venous blood were collected. Samples were refrigerated and transported to a local laboratory in each city. Later, samples were centrifuged to separate the serum and were stored at $-30^{\circ} \mathrm{C}$ to $-80^{\circ} \mathrm{C}$ until processing at the reference laboratory at the Instituto Nacional de Salud. The detection of total antibodies was made by the chemiluminescence technique (CLIA) 'SARS-CoV-2 Total Advia Centaur-Siemens'. The Advia Centaur-Siemen's test detects serum total antibodies against SARS-CoV-2. According to the manufacturer, the range of index values oscillates between 0.05 and 10 (cut-off point of reactive $=>10$ ).

The CLIA test was selected after performing a secondary validation with samples from the Colombian population. The sensitivity and specificity of the test were $86 \%$ (95\% CI 79\% to 91\%) and $99 \%$ (95\% CI $96 \%$ to $100 \%$ ), respectively. ${ }^{19}$

\section{COLLECTION OF SAMPLES AND FIELD SURVEYS}

An electronic questionnaire was applied online using Google Forms. The questions were based on the guidelines from the WHO. ${ }^{18}$ The questionnaire included questions for sociodemographic characterisation, usage of personal protective equipment, characterisation of work conditions and dwelling, and previous exposure to COVID-19. Also, participants who declared having had COVID-19 were asked whether their insurance recognised their COVID-19 episode as being work related.

Five experts were asked to perform a virtual judgement to validate the content of the instrument. ${ }^{20}$ The criteria included clarity, coherence, relevance and sufficiency. The criteria were evaluated on a scale of $1-5$ by each expert. Finally, the questionnaire was validated by $300 \mathrm{HCW}$ from Bogota. A Spanish version of the questionnaire is available (online supplemental material 1).

\section{STATISTICAL ANALYSIS}

Sociodemographic characteristics of HCWs were described for each city. For the quantitative variables, means and SD were estimated. Subsequently, a bivariate analysis was performed comparing the nominal or ordinal variables regarding the presence or absence of antibodies against SARS-CoV-2, analysed using Pearson's $\mathrm{X}^{2}$ test with Yates correction. In the case of quantitative variables, the Spearman correlation was used. The level of statistical significance established was $\mathrm{p}<0.05$.

A Poisson regression model was applied to test the relationship between the results of the CLIA tests (dependent variable) and the independent variables. Independent variables were selected from the bivariate results. Variables with a $p<0.2$ were included in the multivariate model. Associations were presented in prevalence ratios with 95\% CIs. The Akaike information criterion was used as an estimator of the quality of statistical models. ${ }^{21}$

The statistical analysis was conducted using R (V.4.0.3). The overall crude frequencies of seropositivity tests were estimated. Later, the crude seroprevalence was stratified by age, sex, ethnicity and role at the IPS. For both cases, crude seroprevalence was adjusted using the Bayesian method in R V.2.21.2 (pack RStan $)^{22}$ using the data of sensitivity and specificity reported in previous studies carried out using CLIA in Colombian populations. ${ }^{19}$ Also, 95\% Bayesian credibility intervals (BCIs) were obtained. 


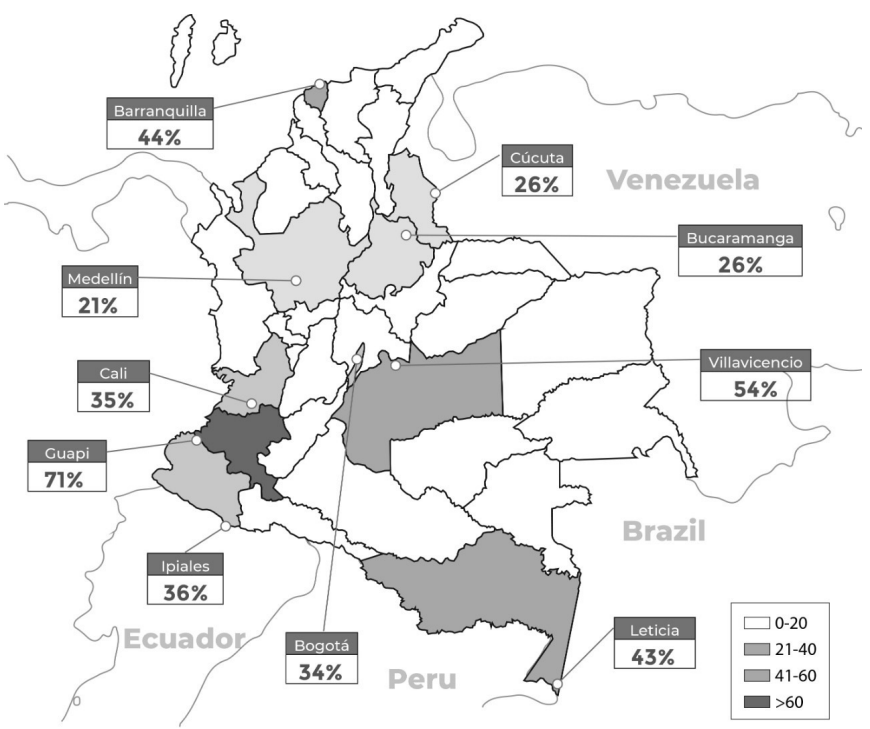

Figure 1 Distribution of seroprevalence by city. The figure presents in greyscale the prevalence of antibodies against SARS-CoV-2 in each city included in the study. Cities are marked with a white dot. The greater the intensity of the grey, the greater the seroprevalence was found in the city.

The model was run according to the following equation:

Real prevalence $=$ adjusted prevalence $\times$ sensitivity $+(1-$ adjusted prevalence $) \times(1-$ specificity) (see online supplemental file 2).

\section{RESULTS}

\section{Sociodemographic description}

A total of $4042 \mathrm{HCW}$ s were included in the study in 65 health centres from 10 cities. The questionnaire was completed by $82 \%$ $(n=3294)$ of the participants. The mean age was $36.45 \pm 10.5$ years old. Most of the participants belonged to socioeconomic strata 2 and $3(63.4 \%)$. Most of the participants were nurses $(34.9 \%)$ and general practitioners $(10.1 \%)$. The distribution of participants by cities were Bogotá $(n=677 ; 16.7 \%)$, Bucaramanga $(n=508 ; 12.6 \%)$, Cali $(n=500 ; 12.4 \%)$, Medellín $(n=470 ; 11.6 \%)$, Barranquilla $(n=434 ; 10.7 \%)$, Cucuta $(n=423$; $10.5 \%)$, Villavicencio $(n=395 ; 9.8 \%)$, Ipiales $(n=388 ; 9.6 \%)$, Leticia $(n=176 ; 4.4 \%)$ and Guapi $(n=71 ; 1.8 \%)$ (figure 1$)$.

\section{SARS-CoV-2 prevalence}

The prevalence of self-declared SARS-CoV-2 infection was $30.06 \%$ (95\% CI $29.01 \%$ to $32.22 \%$; $n=995)$. The percentage of workers who declared having been diagnosed with the PCR test was $89.54 \%(95 \%$ CI $87.49 \%$ to $91.3 \% ; n=891)$. The proportion of seropositivity among the workers who declared the COVID-19 infection was $81 \%$ (95\% CI $77.50 \%$ to $84.0 \%$ ). The proportion of workers who received legal recognition of COVID-19 infection as a work-related disease was $40.60 \%$ (95\% CI $37.50 \%$ to $43.70 \%$; $n=404)$.

\section{Protective equipment}

The adherence to using protective equipment such as face masks (disposable surgical and N95 masks) was 100\% among HCWs. It was observed that male participants tend to perform a lower number of protective elements $\left(X^{2}=44.69, p=0.00001\right)$. Participants who declared having been vaccinated against influenza during the last year have a lower proportion of seroconversion than those who did not receive the vaccine $\left(X^{2}=9.7425\right.$, $\mathrm{p}=0.0001)$.

\section{Seroprevalence of SARS-CoV-2 in HCWs}

The global seroprevalence was 35\% (95\% BCI 33.0\% to 37.0\%). The highest seroprevalence by cities was found in Guapi (71\%), Villavicencio (54\%) and Barranquilla (44\%) (table 1). No significant difference was found between male and female HCWs concerning seropositivity. In the bivariate analysis, there was an association between seroprevalence and occupation, age, socioeconomic strata and educational level $(\mathrm{p}<0.05)$ (table 1$)$. There was an association between seropositivity and families with two or more members $\left(X^{2}=7.74 ; p=0.005\right)$.

The seropositivity was higher among personnel from general services (48\%; 95\% CI 37\% to 59\%) and nurses (46\%; 95\% CI $42 \%$ to $49 \%$ ) (figure 2). The occupation with the lowest seropositivity rate was physiotherapist $(7 \%$; $95 \%$ CI $0 \%$ to $18 \%)$. A reversed social gradient was found out between the presence of antibodies against SARS-CoV-2 and socioeconomic level $\left(X^{2}=100.87\right.$; $p$ trend $\left.=0.0000001\right)$ (figure 3).

The multivariate model showed that participants from lower socioeconomic strata have more chance of having a reactive CLIA test (table 2). Besides, HCWs with blood type $\mathrm{AB}$ compared with type $\mathrm{O}$ were $68 \%$ more likely to have a reactive CLIA test. People who work in the emergency room and hospitalisation were more likely to have a reactive CLIA test (by $57 \%$ and $37 \%$, respectively). Participants who worked in the ICU and COVID-19 services had not increased their risk of having a reactive test and were not significant in the multivariate model (table 2).

\section{DISCUSSION}

HCWs are a population with a high-risk of acquiring SARSCoV-2 infection due to direct contact with patients. ${ }^{723}{ }^{24} \mathrm{We}$ conducted a study to assess the seroprevalence of SARS-CoV-2 infection associated with characteristic demographics and the occupation of HCWs from 65 hospitals and medical centres in 10 Colombian cities. We observed an overall seroprevalence of $32 \%$. Except for Bucaramanga (26\%), the seroprevalence was higher among workers in cities with less than 1.5 million inhabitants: Guapi (71\%), Villavicencio (54\%), Leticia (43\%) and Ipiales (37\%). The seroprevalence in cities with larger populations was lower: Bogotá (34\%), Cali (35\%), Cúcuta (27\%) and Medellín (22\%).

Comparing our findings with the reported seroprevalence of SARS-CoV-2 antibodies in the general population in Colombia (September-December 2020), ${ }^{25}$ except for Bucaramanga (32\%), the seroprevalence in the HCWs tended to be lower in cities located in the North region (Barranquilla 55\%, Cúcuta 40\% and Medellín 27\%). Nevertheless, the seroprevalence of SARSCoV-2 antibodies in HCWs in cities from the Central, Southern and Western region of the country was higher than that reported in the general population (Bogota 30\%, Leticia 59\%, Villavicencio 34\%, Guapi 68\% and Ipiales 35\%). ${ }^{25}$

The seroprevalence in HCWs from Bogota was higher than in a previous study in one hospital in the city carried out in August $2020(8.26 \%)^{26}$ but similar to the seroprevalence reported in a cohort of airport workers in Bogotá (September 2020). ${ }^{27}$

The reported seroprevalence of antibodies against SARS$\mathrm{CoV}-2$ in HCWs was greater than that reported in the studies conducted during the second semester of 2020 in North America (12.7\%), Africa (8.2\%) and Asia (4\%). ${ }^{28}$ Besides, reports from studies carried out in European countries are lower than 
Table 1 Demographics, symptomatology, occupational exposure and seroprevalence in healthcare workers in Colombia

\begin{tabular}{|c|c|c|c|c|c|c|}
\hline \multirow[b]{2}{*}{ Variable } & \multirow[b]{2}{*}{ Sample size, $n$} & \multirow[b]{2}{*}{ Seropositive participants, $\mathbf{n}$} & \multicolumn{2}{|l|}{ Seroprevalence } & \multirow[b]{2}{*}{$\mathbf{X}^{2}$} & \multirow[b]{2}{*}{$P$ value } \\
\hline & & & Crude & Adjusted & & \\
\hline \multicolumn{7}{|l|}{ Age group (years) } \\
\hline $31-40$ & 1120 & 376 & 0.33 (0.30 to 0.36$)$ & $0.38(0.35$ to 0.41$)$ & & \\
\hline $41-50$ & 663 & 197 & $0.29(0.26$ to 0.33$)$ & 0.33 (0.29 to 0.28$)$ & & \\
\hline $51-60$ & 397 & 85 & $0.21(0.17$ to 0.25$)$ & 0.23 (0.19 to 0.28$)$ & & \\
\hline Male & 788 & 246 & 0.31 (0.28 to 0.34$)$ & 0.35 (0.31 to 0.39$)$ & & \\
\hline \multicolumn{7}{|l|}{ Socioeconomic strata } \\
\hline 1 (lowest) & 529 & 233 & 0.44 (0.39 to 0.48$)$ & 0.51 (0.45 to 0.55$)$ & 104.35 & 0.000 \\
\hline 2 & 1044 & 373 & 0.35 (0.32 to 0.38$)$ & 0.41 (0.37 to 0.44$)$ & & \\
\hline 3 & 1098 & 305 & $0.27(0.25$ to 0.30$)$ & 0.31 (0.27 to 0.34$)$ & & \\
\hline Afro-Colombian & 216 & 87 & 0.40 (0.33 to 0.47$)$ & $0.46(0.38$ to 0.53$)$ & 21.049 & 0.179 \\
\hline White & 995 & 290 & $0.29(0.26$ to 0.32$)$ & $0.33(0.29$ to 0.36$)$ & & \\
\hline Indigenous & 112 & 46 & $0.41(0.31$ to 0.50$)$ & 0.47 (0.36 to 0.58$)$ & & \\
\hline Mestizo & 2004 & 606 & $0.30(0.28$ to 0.32$)$ & $0.34(0.31$ to 0.36$)$ & & \\
\hline Raizal & 19 & 5 & $0.26(0.10$ to 0.51$)$ & $0.29(0.05$ to 0.53$)$ & & \\
\hline Gipsy & 6 & 2 & 0.33 (0.05 to 0.75$)$ & - & & \\
\hline Others & 27 & 14 & $0.51(0.32$ to 0.70$)$ & $0.6(0.37$ to 0.82$)$ & & \\
\hline \multicolumn{7}{|l|}{ Educational level } \\
\hline Bachelor & 235 & 96 & 0.40 (0.34 to 0.47$)$ & 0.47 (0.39 to 0.54$)$ & 91.021 & 0.000 \\
\hline Specialisation & 524 & 91 & $0.17(0.14$ to 0.20$)$ & $0.19(0.14$ to 0.22$)$ & & \\
\hline Adult ICU & 309 & 84 & $0.27(0.22$ to 0.32$)$ & $0.30(0.24$ to 0.36$)$ & 58.994 & 0.000 \\
\hline General services & 21 & 7 & $0.33(0.15$ to 0.56$)$ & $0.37(0.13$ to 0.61$)$ & & \\
\hline Reference and counter-reference & 49 & 14 & 0.28 (0.17 to 0.43$)$ & 0.32 (0.16 to 0.47$)$ & & \\
\hline Radiology & 55 & 16 & 0.29 (0.18 to 0.43$)$ & 0.32 (0.18 to 0.47$)$ & & \\
\hline Laboratory & 150 & 32 & 0.21 (0.15 to 0.28 ) & 0.23 (0.15 to 0.31$)$ & & \\
\hline Hospitalisation & 761 & 251 & $0.32(0.29$ to 0.36$)$ & 0.37 (0.33 to 0.41$)$ & & \\
\hline Pharmacy & 15 & 2 & 0.13 (0.02 to 0.41$)$ & 0.13 (0.00 to 0.34$)$ & & \\
\hline External consultation & 306 & 83 & $0.27(0.22$ to 0.32$)$ & $0.30(0.24$ to 0.36$)$ & & \\
\hline Surgery & 128 & 41 & $0.32(0.24$ to 0.40$)$ & $0.36(0.26$ to 0.45$)$ & & \\
\hline \multicolumn{7}{|l|}{ City } \\
\hline Bogotá & 677 & 204 & 0.30 (0.26 to 0.33$)$ & 0.34 (0.30 to 0.38$)$ & 146.87 & 0.000 \\
\hline Barranquilla & 434 & 167 & 0.38 (0.33 to 0.43$)$ & 0.44 (0.39 to 0.50$)$ & & \\
\hline Bucaramanga & 508 & 118 & 0.23 (0.19 to 0.27 ) & $0.26(0.21$ to 0.30$)$ & & \\
\hline Cali & 500 & 154 & 0.31 (0.26 to 0.35$)$ & 0.35 (0.30 to 0.40$)$ & & \\
\hline Cúcuta & 423 & 100 & 0.24 (0.19 to 0.28$)$ & $0.26(0.21$ to 0.31$)$ & & \\
\hline Medellín & 470 & 91 & 0.19 (0.15 to 0.23$)$ & 0.21 (0.17 to 0.25$)$ & & \\
\hline Villavicencio & 395 & 186 & 0.47 (0.42 to 0.52$)$ & 0.54 (0.49 to 0.60$)$ & & \\
\hline Leticia & 176 & 66 & 0.38 (0.30 to 0.45$)$ & 0.43 (0.34 to 0.52$)$ & & \\
\hline Ipiales & 388 & 124 & 0.32 (0.27 to 0.36$)$ & 0.36 (0.31 to 0.42$)$ & & \\
\hline Guapi & 71 & 43 & 0.61 (0.48 to 0.71$)$ & 0.71 (0.57 to 0.84$)$ & & \\
\hline
\end{tabular}

Sociodemographic characteristics of the participants in the study. The table also reports the crude seroprevalence and $95 \% \mathrm{Cls}$.

$\mathrm{ICU}$, intensive care unit. 


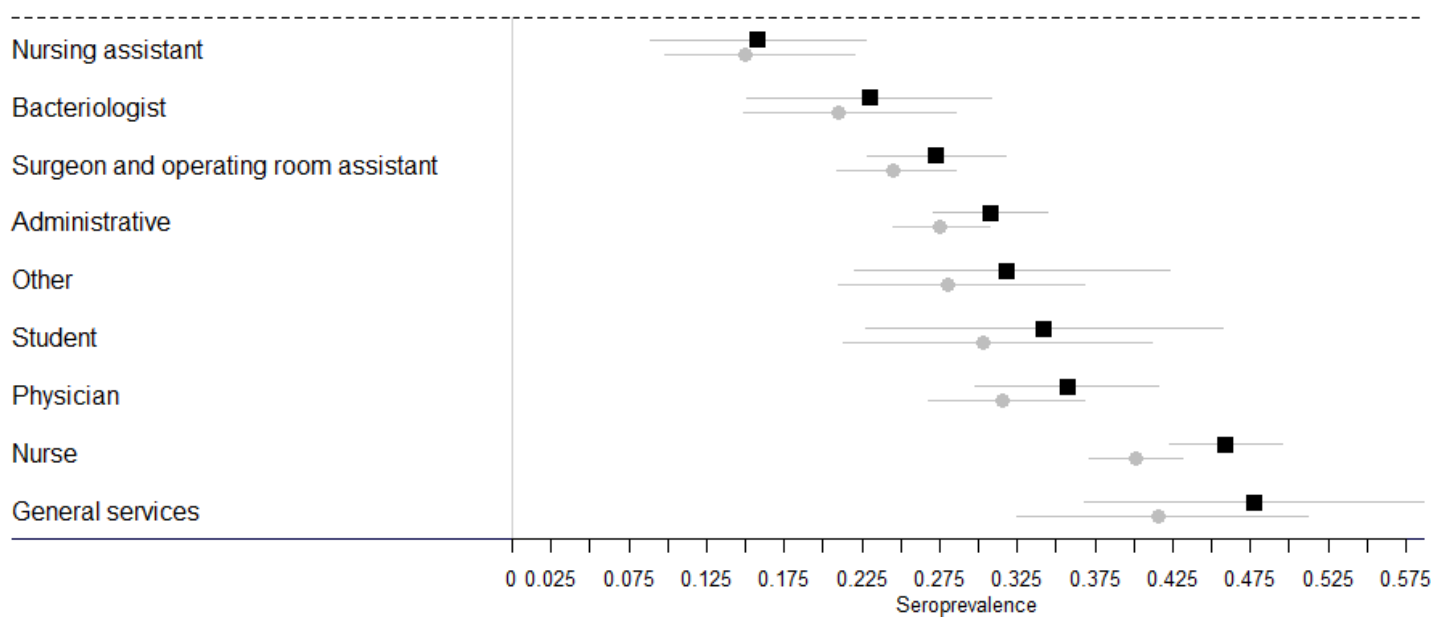

Figure 2 Seroprevalence among healthcare workers in Colombia by occupation. * Other: nutritionists, Rx technician, physiotherapist and clinical laboratory technician. The figure shows the crude and adjusted seroprevalence levels among different healthcare occupations. Seroprevalence levels were higher among nurses and general services workers.

our results: Denmark (4.04\%), England (24.4\%), Germany $(4.36 \%),{ }^{29}$ Greece $(1.26 \%),{ }^{30}$ Italy $(14.4 \%)$ and Switzerland $(1 \%) .^{31}$

We have found no differences in the distribution of seroprevalence between men and women. This issue has been approached in several seroprevalence studies. A recent meta-analysis has reported that seroprevalence levels were higher among male HCWs. ${ }^{11}$ Another systematic review observed higher seroprevalence ratios among men. ${ }^{28}$ This association may be correlated with the fact that men tend to show less adherence to protective protocols compared with women. ${ }^{32}$ In our study, we observed that men seem to be less willing to use all personal protection items compared with women.

Also, we observed that occupations that are performed mostly by women were associated with a higher risk of infection. It has been stated that gender is a social determinant of health, linked to the health disparities among the COVID-19 pandemic. ${ }^{33}$ Also, it was highlighted that personal protective equipment does not protect female HCWs as well as their male colleagues. It has been pointed out, for example, that the glasses do not fit their faces, the gloves are too long and the face shields collide with the chest, making it uncomfortable to perform procedures. ${ }^{34} 35$ These conditions constitute a relevant concern considering that the COVID-19 pandemic has highlighted the extent to which society depends on women, both in the first line of response in the health sector, as well as at homes. Women constitute the majority of the workforce in the health sector ${ }^{36}$ and in Colombia, more than $70 \%$ of HCWs are women. ${ }^{37}$ Nevertheless, these statistics do not include personnel involved in activities of cleaning and catering. Women have an increased risk of contracting SARS$\mathrm{CoV}-2$ given the close interaction with patients and visitors amid shortages of personal protective equipment. ${ }^{33}$ Also, women are

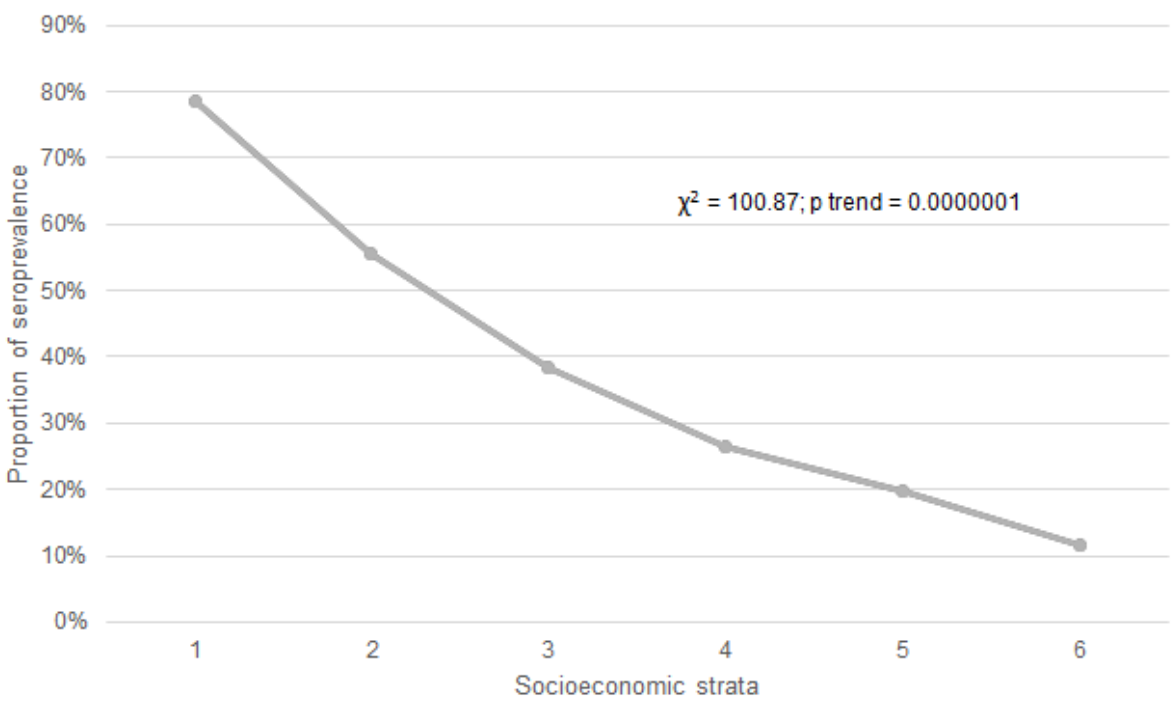

Figure 3 Seroprevalence and socioeconomic stratum in Colombia. The figure presents the differences in the seroprevalence of antibodies against SARSCoV-2 among healthcare workers from different socioeconomic levels. There is a linear trend showing higher seroprevalence levels in lower socioeconomic strata (1-3) and lower seroprevalence in higher socioeconomic strata (4-6). 


\begin{tabular}{|c|c|c|}
\hline Variable & Prevalence ratios $(95 \% \mathrm{Cl})$ & $P$ value \\
\hline \multicolumn{3}{|l|}{ Age (years) } \\
\hline$<30$ & 1 & -- \\
\hline $31-59$ & 0.93 (0.81 to 1.08 ) & 0.382 \\
\hline$>60$ & $0.76(0.43$ to 1.34$)$ & 0.350 \\
\hline \multicolumn{3}{|l|}{ Sex } \\
\hline Female & 1 & - \\
\hline Male & 1.04 (0.89 to 1.22$)$ & 0.572 \\
\hline \multicolumn{3}{|l|}{ Socioeconomic strata } \\
\hline 6 (highest) & 1 & - \\
\hline 1 (lowest) & 3.15 (1.45 to 6.84$)$ & 0.003 \\
\hline 2 & 2.87 (1.34 to 6.16$)$ & 0.006 \\
\hline 3 & 2.31 (1.08 to 4.95$)$ & 0.030 \\
\hline 4 & 1.90 (0.87 to 4.13$)$ & 0.106 \\
\hline 5 & 1.83 (0.81 to 4.16$)$ & 0.143 \\
\hline \multicolumn{3}{|l|}{ Blood type } \\
\hline 0 & 1 & - \\
\hline B & $1.06(0.83$ to 1.35$)$ & 0.637 \\
\hline$A B$ & 1.68 (1.12 to 2.52$)$ & 0.011 \\
\hline A & $1.13(0.97$ to 1.30$)$ & 0.102 \\
\hline \multicolumn{3}{|l|}{ Number of jobs } \\
\hline 1 & 1 & - \\
\hline$>1$ & 1.09 (0.91 to 1.32$)$ & 0.333 \\
\hline \multicolumn{3}{|l|}{ Service } \\
\hline Administrative & 1 & - \\
\hline Emergency & 1.57 (1.28 to 1.92$)$ & 0.000 \\
\hline Paediatric ICU & $1.13(0.70$ to 1.81$)$ & 0.605 \\
\hline Adult ICU & $1.15(0.86$ to 1.53$)$ & 0.325 \\
\hline General services & $1.36(0.55$ to 3.35$)$ & 0.496 \\
\hline Radiology & $1.11(0.62$ to 1.97$)$ & 0.713 \\
\hline Clinical laboratory & $0.97(0.65$ to 1.44$)$ & 0.901 \\
\hline Hospitalisation & 1.37 (1.11 to 1.69$)$ & 0.003 \\
\hline Pharmacy & $0.71(0.17$ to 2.91$)$ & 0.643 \\
\hline Ambulatory service & 1.05 (0.78 to 1.41$)$ & 0.725 \\
\hline Surgery & $1.36(0.95$ to 1.96$)$ & 0.087 \\
\hline \multicolumn{3}{|l|}{ Comorbidities } \\
\hline No & 1 & - \\
\hline Yes & 1.00 (0.85 to 1.18$)$ & 0.919 \\
\hline \multicolumn{3}{|l|}{ Tobacco usage } \\
\hline No & 1 & - \\
\hline Former smoker & 1.03 (0.76 to 1.39$)$ & 0.824 \\
\hline Smoker & $0.97(0.73$ to 1.30$)$ & 0.881 \\
\hline \multicolumn{3}{|l|}{ City } \\
\hline Bogotá & 1 & - \\
\hline Bucaramanga & 0.75 (0.58 to 0.97$)$ & 0.028 \\
\hline Villavicencio & 1.46 (1.17 to 1.84$)$ & 0.000 \\
\hline Medellín & 0.74 (0.55 to 0.98$)$ & 0.038 \\
\hline Cali & 1.00 (0.76 to 1.33$)$ & 0.956 \\
\hline Cúcuta & 0.72 (0.55 to 0.94$)$ & 0.016 \\
\hline Barranquilla & 1.18 (0.90 to 1.55$)$ & 0.224 \\
\hline Guapi & 1.60 (1.09 to 2.34$)$ & 0.014 \\
\hline Leticia & 0.00 (0.00 to 2.75$)$ & 0.968 \\
\hline Ipiales & 0.90 (0.69 to 1.16$)$ & 0.427 \\
\hline \multicolumn{3}{|l|}{ Household size (people) } \\
\hline 1 & 1 & - \\
\hline$>1$ & 1.05 (1.00 to 1.12$)$ & 0.050 \\
\hline
\end{tabular}

Results of multiple Poisson regression of the association between seropositivity to SARSCoV-2 and sociodemographic characteristics. Prevalence ratios estimated using the best fitting model are reported.

$\mathrm{ICU}$, intensive care unit. concentrated in roles requiring the closest, prolonged contact with patients. ${ }^{38}$

We did not observe differences in seroprevalence levels regarding ethnicity. Nevertheless, several authors have reported that exposition levels are higher among Afro-Americans and Hispanics. $^{112839}$

Also, an association between the presence of antibodies in serum and the social stratum in which the worker resides was found. It was observed that there is a reverse gradient in the seroprevalence proportion; as far as the stratum increases, the proportion of people with a reactive test for antibodies decreases. These findings have been previously described at the community level, showing the association between socioeconomic aspects and COVID-19 transmission, ${ }^{40}$ COVID-19 severity ${ }^{41}$ and antibody presence. ${ }^{42}$ Nevertheless, to our knowledge, this is the first report showing the links between seroprevalence and socioeconomic strata among the HCWs. A study carried out among a group of workers with high risk of SARS-CoV-2 transmission has stated that prevention programmes should include extra labour factors such as including recommendations for biological protection at home, supermarket and other places. ${ }^{43}$ In this sense, various authors have indicated that most of the COVID-19 cases took place in places such as homes. ${ }^{44} 45$ Considering that only $40 \%$ of the self-declared COVID-19 cases were recognised as linked to occupational activities, extra occupational risk factors such as positive close contact at home, family size and house conditions should be studied in detail to understand the SARSCoV-2 transmission in HCWs. ${ }^{46}$

Additionally, the regression model found out that participants who work in the emergency room and hospitalisation were more likely to have antibodies against SARS-CoV-2. Conversely, workers from the ICU and COVID-19 services had not increased their risk of having a reactive test. These findings differ from the literature reports which have stated that people working on COVID-19 units have an increased risk of having a positive SARS-CoV-2 antibody test. ${ }^{8478}$ Nevertheless, our results have shown that participants who work in emergency services showed a significant increase in the risk of having an antibody reactive test. A\&E characteristics vary depending on the location, clinical specialties and availability of technology. Most of the emergency services in Colombia have not divided the attention of respiratory cases from other emergencies. Also, patients could stay for longer periods waiting for diagnosis, treatment or transference. These work conditions may increase the exposure risk of HCWs in emergency areas.

Studies have shown a slightly increased infection among non-O types. Also, the risk of intubation decreased in type A. ${ }^{49}$ Here, we observed an increased risk in the AB blood types. However, this result may contribute to the knowledge of blood type and the relationship with the role of the infection with COVID-19.

The present study has limitations. First, the aspects related to the design of the research. A cross-sectional study was formulated and carried out between September and December 2020. Also, the characteristics of the sampling may introduce a selection bias among the workers who have been previously infected. Second, the HCWs answered the survey in different moments of the pandemic, even several months after having the COVID-19 episode, which may introduce a recall bias. Likewise, we do not control or implement so methodology to determine if the exposure was occupational or if the disease was caused outside the medical centres. In addition, the test used to identify antibodies against SARS-COV-2 did not allow quantifying the differences in antibody titres among the reactive participants. In this sense, we could not perform an analysis including the role that the job 
position played in the generation or not of antibodies against SARS-CoV-2. Since the study used the declared information related to COVID-19 antecedent, it was not possible to determine how many of those who tested positive at CLIA had also a previous molecular test positive for SARS-CoV-2 infection. Finally, the study did not evaluate the inadequate use of personal protective equipment that has been associated with an increased risk of COVID-19. ${ }^{50-52}$ Moreover, the source of contagion was not determined in the study, though it could be a main key issue to the protection and to ensure treatment and recovery of the health workers.

In conclusion, to our knowledge, this is the first national study to quantify the level of seropositivity to SARS-CoV-2 in HCWs in the Andean region. The impact of the transmission on HCWs varies significantly from one city to another. Our findings have important implications for understanding the spread of SARSCoV-2 and for planning control programmes in this population, as it could be the information of seroprevalence before the introduction of the SARS-CoV-2 vaccine.

\section{Author affiliations}

'Doctorado en Salud Pública, El Bosque University Faculty of Medicine, Bogota, Colombia

${ }^{2}$ Grupo de investigación en Salud Ambiental y Laboral, Instituto Nacional de Salud, Bogotá, Colombia

${ }^{3}$ Research Directorate, National Institute of Health, Bogota, Colombia

${ }^{4}$ Faculty of Nursing, National University of Colombia, Bogota, Colombia

${ }^{5}$ El Bosque University Faculty of Medicine, Bogota, Colombia

${ }^{6}$ Red de Investigación, Innovación y Desarrollo en Seguridad y Salud en el Trabajo, Bogota, Colombia

${ }^{7}$ Immunotoxicology Research Group, National University of Colombia—Bogota, Bogota, Colombia

${ }^{8}$ National Open and Distance University, Bucaramanga, Colombia

${ }^{9}$ Red de Investigación, Innovación y Desarrollo en Seguridad y Salud en el Trabajo, Bogotá, Colombia

${ }^{10}$ School of Medicine, Universidad del Norte, Barranquilla, Colombia

Twitter Jeadran Nevardo Malagón-Rojas @jeadranmalagon

Acknowledgements The authors thank the hundreds of volunteers, community leaders, health institutions and the thousands of participants of the study. Special thanks to Secretarias de Salud Distritales and Secretarias de Salud Departamentales from the cities involved in the study. Special thanks to the public institutions, Armada Nacional de Colombia, Policía Nacional de Colombia, Fontur, SATENA, and civil organisations that facilitated the transfers of personnel in the field and the logistics of the study in each city. Special recognition for the support of the field epidemiologists' team of the Field-Epidemiology-Training-Program (FETP) from Colombia. Also, a special thanks to healthcare workers of all medical centres in the country who have treated patients with COVID-19 since the beginning of the pandemic. Recognition and honours to the health personnel who lost their lives in this noble fight and to those who continue in this tough challenge. Authors want to thank Owen Harrison for his valuable comments in the final version of the manuscript. Finally, JNM-R would like to express his sincere gratitude to Carolina Garrote, Manuel Cruz and Victoria Malagón.

Collaborators Interinstitutional Support Group: Magdalena Weisner, Gloria Puerto, Lyda Muñoz-Galindo, María Teresa Herrera, Jhonantan Reales, Edwin CárdenasVillamil, Jessica Ortíz, Ligia Ovideo and Liliana Serrano, Stephany Botero, Helena María Rodríguez-Perea, Norma, Celis-Cruz and Juan Felipe Bedoya.

Contributors JNM-R, MM-R, ELPB, ET, CPJ, LGD-M, DV-P, LL and EM designed the study. JNM-R, MM-R, JA, VVR, MG, El, YGT-P, RL, MP and ELPB conducted the analysis and developed the first draft of the manuscript, and edited the paper according to coauthors' suggestions. DV-P, EM and LGD-M provided their technical input to improve the final manuscript. All authors contributed to the final draft of the manuscript. JNM-R and MM-R accepts full responsibility for the finished article, had access to any data, and controlled the decision to publish.

Funding The present research was financed by the Instituto Nacional de Salud.

Map disclaimer The depiction of boundaries on the map(s) in this article does not imply the expression of any opinion whatsoever on the part of BMJ (or any member of its group) concerning the legal status of any country, territory, jurisdiction or area or of its authorities. The map(s) are provided without any warranty of any kind, either express or implied.
Competing interests None declared.

Patient consent for publication Not required.

Ethics approval The study proposal and protocol were approved by the ethics committee of Instituto Nacional de Salud (CEMIN 012/2020) and the Research Ethics Committee from Universidad del Norte (223/10/2020). We have obtained written informed consent from each participant in the study.

Provenance and peer review Not commissioned; externally peer reviewed.

Data availability statement Data are available upon reasonable request. Data may be obtained from a third party and are not publicly available.

Supplemental material This content has been supplied by the author(s). It has not been vetted by BMJ Publishing Group Limited (BMJ) and may not have been peer-reviewed. Any opinions or recommendations discussed are solely those of the author(s) and are not endorsed by BMJ. BMJ disclaims all liability and responsibility arising from any reliance placed on the content. Where the content includes any translated material, BMJ does not warrant the accuracy and reliability of the translations (including but not limited to local regulations, clinical guidelines, terminology, drug names and drug dosages), and is not responsible for any error and/or omissions arising from translation and adaptation or otherwise.

Open access This is an open access article distributed in accordance with the Creative Commons Attribution Non Commercial (CC BY-NC 4.0) license, which permits others to distribute, remix, adapt, build upon this work non-commercially, and license their derivative works on different terms, provided the original work is properly cited, appropriate credit is given, any changes made indicated, and the use is non-commercial. See: http://creativecommons.org/licenses/by-nc/4.0/.

\section{ORCID iDs}

Jeadran Nevardo Malagón-Rojas http://orcid.org/0000-0001-5801-936X

Yezith G Toloza-Pérez http://orcid.org/0000-0001-9514-7192

Eliana L Parra Barrera http://orcid.org/0000-0002-2745-7997

Marien Palma http://orcid.org/0000-0001-8494-7370

Ronald López http://orcid.org/0000-0001-7646-4184

Julia Almentero http://orcid.org/0000-0001-7203-8380

Vivian V Rubio http://orcid.org/0000-0002-7487-1891

Eliana Téllez http://orcid.org/0000-0001-7421-0439

Lucy G Delgado-Murcia http://orcid.org/0000-0003-2947-7796

Diego Viasus-Pérez http://orcid.org/0000-0001-8408-3947

Marisol Galindo http://orcid.org/0000-0002-3473-8703

Luisa Lagos http://orcid.org/0000-0001-9714-565X

\section{REFERENCES}

1 World Health Organization. Keep health workers safe to keep patients safe: who. Available: https://www.who.int/news/item/17-09-2020-keep-health-workers-safe-tokeep-patients-safe-who [Accessed 8 Feb 2021]

2 Erdem H, Lucey DR. Healthcare worker infections and deaths due to COVID-19: a survey from 37 nations and a call for who to post national data on their website. Int $J$ Infect Dis 2021:102:239-41.

3 Venugopal U, Jilani N, Rabah S, et al. SARS-CoV-2 seroprevalence among health care workers in a new York City Hospital: a cross-sectional analysis during the COVID-19 pandemic. Int J Infect Dis 2021;102:63-9.

4 Kataria Y, Cole M, Duffy E, et al. Seroprevalence of SARS-CoV-2 IgG antibodies and risk factors in health care workers at an academic medical center in Boston, Massachusetts. Sci Rep 2021;11:9694.

5 Takita M, Matsumura T, Yamamoto K. Preliminary results of seroprevalence of SARSCoV-2 at community clinics in Tokyo. Infectious Diseases 2020

6 Self WH, Tenforde MW, Stubblefield WB, et al. Seroprevalence of SARS-CoV-2 among frontline health care personnel in a multistate Hospital network - 13 academic medical centers, April-June 2020. MMWR Morb Mortal Wkly Rep;69:1221-6.

7 Garcia-Basteiro AL, Moncunill G, Tortajada M, et al. Seroprevalence of antibodies against SARS-CoV-2 among health care workers in a large Spanish reference Hospital. Nat Commun 2020;11:3500.

8 Kassem AM, Talaat H, Shawky S, et al. SARS-CoV-2 infection among healthcare workers of a gastroenterological service in a tertiary care facility. Arab J Gastroenterol 2020;21:151-5.

9 Bogogiannidou Z, Vontas A, Dadouli K, et al. Repeated leftover serosurvey of SARS CoV-2 IgG antibodies, Greece, March and April 2020. Euro Surveill 2020;25.

10 Canova V, Lederer Schläpfer H, Piso RJ, et al. Transmission risk of SARS-CoV-2 to healthcare workers -observational results of a primary care hospital contact tracing. Swiss Med Wkly 2020;150:w20257.

11 Kayı IIlker, Madran B, Keske Şiran, I K, Ş K, et al. The seroprevalence of SARS-CoV-2 antibodies among health care workers before the era of vaccination: a systematic review and meta-analysis. Clin Microbiol Infect 2021;27:S1198743X21002846.

12 Instituto Nacional de Salud. Estimación del número reproductivo efectivo RT para COVID-19 en Colombia, 2020. Available: https://www.ins.gov.co/Direcciones/ONS/ modelos-de-estimacion [Accessed 19 Jan 2021]. 
13 World Health Organization. WHO Director-General's opening remarks at the media briefing on COVID-19 - 11 January 2021, 2020. Available: https://www.who.int/ director-general/speeches/detail/who-director-general-s-opening-remarks-at-themedia-briefing-on-covid-19-11-january-2021 [Accessed 8 Feb 2021].

14 Rivett L, Sridhar S, Sparkes D, et al. Screening of healthcare workers for SARSCoV-2 highlights the role of asymptomatic carriage in COVID-19 transmission. Elife 2020;9:e58728.

15 Oran DP, Topol EJ. Prevalence of Asymptomatic SARS-CoV-2 Infection : A Narrative Review. Ann Intern Med 2020;173:362-7.

16 Mercado M, Malagón-Rojas J, Delgado G, et al. Evaluation of nine serological rapid tests for the detection of SARS-CoV-2. Rev Panam Salud Pública 2020;44:1.

17 von EE, Altman DG, Egger M. The strengthening the reporting of observational studies in epidemiology (STROBE) statement: guidelines for reporting observational studies. The Lancet 2007;370:1453-7.

18 World Health Organization. COVID-19: occupational health and safety for health workers. Geneva, 2020. Available: https://www.who.int/publications-detail-redirect/ WHO-2019-nCoV-HCW advice-2021.1 [Accessed 8 Feb 2021].

19 Mercado-Reyes M, Zabaleta G. Validación secundaria y verificación del desempeño de la prueba serológica "SARS-CoV-2 Total (COV2T) Advia Centaur - Siemens, 2020. Available: https://www.ins.gov.co/Direcciones/Investigacion/Informacionsobrepruebas/ Pruebas\%20serol\%C3\%B3gicas\%20CLIA\%20y\%20ELISA/2-Validacion_prueba_ serologica_SARS-CoV-2_Total_COV2T_Advia_Centaur_Siemens.pdf [Accessed 19 Jan 2021].

20 Galicia Alarcón LA, Balderrama Trápaga JA, Edel Navarro R. Content validity by experts judgment: proposal for a virtual tool. Apertura 2017;9:42-53.

21 Dziak JJ, Coffman DL, Lanza ST, et al. Sensitivity and specificity of information criteria. Brief Bioinform 2020;21:553-65.

22 Gelman A, Carpenter B. Bayesian analysis of tests with unknown specificity and sensitivity. J R Stat Soc C 2020;69:1269-83.

23 Xu X, Sun J, Nie S, et al. Seroprevalence of immunoglobulin M and $\mathrm{G}$ antibodies against SARS-CoV-2 in China. Nat Med 2020;26:1193-5.

24 Steensels D, Oris E, Coninx L, et al. Hospital-Wide SARS-CoV-2 antibody screening in 3056 staff in a tertiary center in Belgium. JAMA 2020;324:195-7.

25 Instituto Nacional de Salud. Seroprevalencia de SARS-CoV-2 durante La epidemia en Colombia: estudio de país, 2021. Available: http://www.ins.gov.co/BibliotecaDigital/ Informe-seroprevalencia-SARS-CoV-2-durante-la-epidemia-en-Colombia.pdf [Accessed 17 Feb 2021].

26 Ariza BE, Torres $Y X$, Salgado D. Seroprevalence and seroconversion rates to SARSCoV-2 in interns, residents, and medical doctors in a university hospital in Bogota, Colombia. medRxiv 2020.

27 Malagón-Rojas JN, Rubio V, Parra-Barrera E. Seroprevalence and Seroconversions for SARS-CoV-2 infections in workers at Bogota Airport, Colombia, 2020. J Travel Med 2021;28:taab006.

28 Galanis P, Vraka I, Fragkou D, et al. Seroprevalence of SARS-CoV-2 antibodies and associated factors in healthcare workers: a systematic review and meta-analysis. J Hosp Infect 2021:108:120-34.

29 Herzberg J, Vollmer T, Fischer B, et al. Prospective sero-epidemiological evaluation of SARS-CoV-2 among health care workers in a German secondary care hospital. Int J Infect Dis 2021;102:136-43.

30 Psichogiou M, Karabinis A, Pavlopoulou ID, et al. Antibodies against SARS-CoV-2 among health care workers in a country with low burden of COVID-19. PLoS One 2020;15:e0243025.

31 Kohler PP, Kahlert CR, Sumer J, et al. Prevalence of SARS-CoV-2 antibodies among Swiss hospital workers: results of a prospective cohort study. Infect Control Hosp Epidemiol 2021:42:1-5.
32 Galasso V, Pons V, Profeta P, et al. Gender differences in COVID-19 attitudes and behavior: panel evidence from eight countries. Proc Natl Acad Sci U SA 2020;117:27285-91.

33 Connor J, Madhavan S, Mokashi M, et al. Health risks and outcomes that disproportionately affect women during the Covid-19 pandemic: a review. Soc Sci Med 2020;266:113364

34 Turner MC, Marshall SD. Can gendered personal protective equipment design account for high infection rates in female healthcare workers following intubation? Anaesthesia 2021;76:132-3.

35 Chakladar A. Personal protective equipment is sexist. The BMJ, 2021. Available: https://blogs.bmj.com/bmj/2021/03/09/personal-protective-equipment-is-sexist/ [Accessed 1 Jul 2021].

36 World Health Organization. Sex distribution of health workers. who, 2020. Available: https://apps.who.int/gho/data/node.main.HWFGRP_BYSEX?lang=en [Accessed 11 Feb 2021].

37 Ministerio de Salud Y Protección social. Indicadores básicos para El seguimiento del talento humano en salud, 2020. Available: http://ontalentohumano.minsalud.gov.co/ indicadores/Paginas/IndicadoresBasicos.aspx [Accessed 11 Feb 2021].

38 Bureau UC. Full-Time, Year-Round workers and median earnings: 2000 and 20132018. U. S, 2000. Available: https://www.census.gov/data/tables/time-series/demo/ industry-occupation/median-earnings.html

39 Selden TM, Berdahl TA. COVID-19 and racial/ethnic disparities in health risk, employment, and household composition: study examines potential explanations for racial-ethnic disparities in COVID-19 hospitalizations and mortality. Health Aff 2020;39:1624-32.

40 Malagón-Rojas J, Ibáñez E, Parra B EL, et al. Analysis of COVID-19 mortality and survival in Colombia: a prospective cohort study. Infectio 2021;25:176.

41 Sesé L, Nguyen Y, Giroux Leprieur E, et al. Impact of socioeconomic status in patients hospitalised for COVID-19 in the greater Paris area. Eur Respir J 2020;56:2002364.

42 Horta B, Silveira M, Barros A, et al. Prevalence of antibodies against SARS-CoV-2 according to socioeconomic and ethnic status in a nationwide Brazilian survey. Rev Panam Salud Publica 2020;44:1-7.

43 Malagón-Rojas J, Parra B EL, Mercado M. Infection and risk perception of SARS-CoV-2 among Airport workers: a mixed methods study. Int J Environ Res Public Health 2020;17:9002.

44 Haroon S, Chandan JS, Middleton J, et al. Covid-19: breaking the chain of household transmission. BMJ 2020;370:m3181.

45 Qian H, Miao T, Liu L. Indoor transmission of SARS-CoV-2. Indoor Air 2020:ina.12766.

46 Milazzo L, Lai A, Pezzati L, et al. Dynamics of the seroprevalence of SARS-CoV-2 antibodies among healthcare workers at a COVID-19 referral hospital in Milan, Italy. Occup Environ Med 2021:oemed-2020-107060.

47 Grant JJ, Wilmore SMS, McCann NS. Seroprevalence of SARS-CoV-2 antibodies in healthcare workers at a London NHS trust. Infect Control Hosp Epidemiol 2020:1-3.

48 Lackermair K, William F, Grzanna N. Infection with SARS-CoV-2 in primary care health care workers assessed by antibody testing. Fam Pract 2020:cmaa078.

49 Zietz M, Zucker J, Tatonetti NP. Associations between blood type and COVID-19 infection, intubation, and death. Nat Commun 2020;11:5761.

50 Nguyen LH, Drew DA, Graham MS, et al. Risk of COVID-19 among front-line healthcare workers and the general community: a prospective cohort study. Lancet Public Health 2020;5:e475-83.

51 Chou R, Dana T, Buckley DI, et al. Epidemiology of and risk factors for coronavirus infection in health care workers: a living rapid review. Ann Intern Med 2020:173:120-36

52 Bielicki JA, Duval X, Gobat N, et al. Monitoring approaches for health-care workers during the COVID-19 pandemic. Lancet Infect Dis 2020;20:e261-7. 